\title{
Possibilities of Using Digital Technologies in Teaching Latin Graphics in the Republic of Kazakhstan
}

\author{
Salgarayeva Gulnaz* Makhanova Aigul, Bazayeva Zhuldyz
}

\author{
Kazakh National Women's Teacher Training University, Almaty, Kazakhstan \\ Corresponding author.Email: gulnaz.salgara@gmail.com
}

\begin{abstract}
This article examines the problems of the transition of the Republic of Kazakhstan to the Latin script and the possibility of using information technology in its solution. After the adoption of Latin graphics, the question of how to teach it will be put in the foreground. In addition, the perception of graphics is carried out by solving problems related to spelling. At this stage, multimedia technologies, in particular, special training programs and mobile applications can become an auxiliary tool in all conditions of life. It is important to establish spelling issues. Modern Kazakh phonemes can be designated by Latin symbols and, accordingly, it is possible to solve the difficulties encountered in the study of the norms of writing, spelling principles by using special training programs, which are created during the research. We hope that the results of this research will contribute to the practice of transition of the Republic of Kazakhstan to writing based on Latin graphics.
\end{abstract}

Keywords: Latin graphics, educational programs, multimedia technologies, linguistics, mobile applications

\section{INTRODUCTION}

Currently, the formation of the task of modernization of public consciousness has led to a practical area: a plan for the adoption of a new alphabet and a phased translation of the Kazakh language into Latin graphics are defined, for Kazakh correspondents had to solve three main issues.

Firstly, the new alphabet should reflect the phonetic structure of the Kazakh language. Currently, the Kazakh alphabet has 42 letters-33 Cyrillic letters and 9 sounds of the Kazakh. On the one hand, according to the laws of linguistics, letters should be less than sounds. According to Kazakh linguists, Latin graphics is convenient for use and accurately reflects the phonetic system of the Kazakh language.

Secondly, the new graphics should lead not only to the consequences of the mechanical replacement of the graphics system, but also lead to a radical reform of the national letter. To do this, it is necessary develop and create a modern national alphabet based on the Latin alphabet, as well as to create new creative writing rules to spell Kazakh and loanwords on the basis of a Single national standard of records.

Thirdly, the new alphabet should make it as easy as possible for Kazakh citizens to use modern computer technologies, which will minimize the special sounds.

To date, Kazakh philologists have developed a working version of the unified standard of the Kazakh alphabet in the proposed Latin script. In the proposed version, only the signs of the Latin alphabet were taken, and today it is actively discussed in all parts of society, as it is one of the most urgent and important problems in the life of every person.

Along with the issues of transition to Latin, graphics there are some problems of spelling. The peculiarities of the designation of Kazakh sounds in the Cyrillic and Latin graphics cause spelling problems. Literacy does not rise to a high level unless these problems are solved. Spelling issues are therefore urgent. Kazakh people in the XX century several times changed the graphics. At these stages, various activities were carried out to learn how to write correctly. Special dictionaries were issued in order to find out the correctness or incorrectness of words, and it was possible to refer only to these dictionaries [1]. Currently, special dictionaries have not eliminated their needs, but new opportunities are opening up associated with the development of technology. Today, using these technologies, it is possible to prepare special mobile applications that are able to correctly write words and find the best solution to spelling problems associated with the transition to Latin graphics.

Information technology include technical, software, information tools, in turn, the technical tools include personal computers, communication networks, network equipment. Depending on the problem of technical equipment, type of information technology allows collecting and processing information and performs functions for assembly, processing, analysis of software directly dependent on technical and information equipment.

In the process of transition to Latin graphics, information technology plays a huge role. In the era of intensive development of information technology, the introduction of Latin graphics in the country should not create serious 
difficulties. This is directly related to the features of the modern information technology environment, communication, and also modern science and the educational process.

Such an example is available in Turkey, which is located in the neighboring and for the first time this experience was acquired by the country Azerbaijan. In Uzbekistan, the transition to Latin graphics was fully completed in 1998. Such experience has been introduced in Turkmenistan. This determines the economic efficiency of the Latin language [2-5].

Taking into account the experience of other countries that have switched to Latin graphics, it is especially important that the features of the original sounds of the Kazakh language are determined by the choice of characters and spelling rules based on morphological characters are correctly developed.

Using multimedia technologies in teaching the Kazakh language based on the Latin graphics.

From the point of view of the Kazakh language, the role of multimedia technologies in it is huge. The Kazakh language including a complex system that obeys different laws: the harmony of language, the harmony of sound. It is difficult for teachers to explain to each of the students such complex topics as stress, influence, grammatical meaning, synharmonism and patterns of phonetic, lexical, grammatical analysis [6]. It that case using information and communication technologies is an indispensable solution to these problems.

One of the main information and communication technologies is an interactive whiteboard, multimedia and online lessons. Currently, teachers gathered from all over the country, open special sites on the Internet, share their experiences, especially online lessons of qualified teachers make a great help to young professionals and teachers in general.

The importance of using an interactive whiteboard in the classroom with which you can solve current problems in the learning process.

In the modern technological society in the educational process of higher education institutions, schools, including the teaching of the Kazakh language, it is necessary to use more information and communication technologies, which is currently in great demand. Among the subjects studied in educational institutions, the Kazakh language occupies a special place. When transition to the Latin alphabet, it should be taken into account that the Kazakh language is a very complex language. In teaching other nationalities, teachers have many difficulties explaining this. Currently, teaching the Kazakh language in schools is one of the main goals. As it is known, various new technologies are used in teaching methods. The purpose of using multimedia technologies in the lessons of the Kazakh language based on Latin graphics is to enrich the vocabulary of students, as well as training in literate writing. Therefore, all teachers should know new approaches in education. The main information technologies used in teaching the Kazakh language are interactive whiteboard, television, e-books. At the present stage of the educational process, the activity of teachers is aimed at continuous improvement of forms and methods of teaching using multimedia technologies. One of the main objectives of the lesson is to develop students ' knowledge and skills. Its solution is implemented through the interactive whiteboard combining innovative and traditional methods of teaching the Kazakh alphabet based on Latin graphics.

Experience with modern computer technology shows that at each stage of the lesson does not require the use of an interactive whiteboard, it depends on the features of the discipline. The teacher gives the results with proper use of interactive boards in improving the efficiency depending on the lesson type and goals on the subject «Kazakh language and literature».

\section{METHODOLOGY RESEARCH}

Latin spelling is also associated with new technology, progress, as all names and e-mails are written in Latin. The main dominance of the implementation of the new alphabet is the view that learning English by learning the official language in the Latin alphabet will be easy. Therefore, it is very important to transition to the Latin alphabet. This process is not inferior to time, and together with the world spaces, without losing its existence, promotes the need for development. Currently, the market of computer devices, smart phones is rapidly developing, it takes time the need to implement new graphics, and now the level of computer literacy is growing significantly among many.

Based on the Memorandum between the Kazakh national women's teacher training University and the Republican specialized boarding school named after Abai for gifted children with in-depth study of the Kazakh language and literature for gifted children, the performers of research work in this school organized an elective course «Latin graphics and Kazakh spelling».

In this course, students not only learn the new Latin alphabet, but also are acquainted with the new rules of spelling, learn to write correctly. In the process of teaching students to literate writing teachers use auditory and visual methods

(Table 
Table 1 Efficiency of using multimedia technologies in the process of elective course «Latin graphics and Kazakh orthography

\begin{tabular}{|c|c|c|}
\hline № & Effective use of multimedia technologies & Effectively moments \\
\hline 1 & Increasing children's interest in the subject & $\begin{array}{l}\text { Using of multimedia technology arouses interest in the } \\
\text { subject. Great influence on the expression of different } \\
\text { sentences. }\end{array}$ \\
\hline 2 & $\begin{array}{l}\text { The ability to quickly obtain the necessary } \\
\text { information }\end{array}$ & $\begin{array}{l}\text { In any environment obtaining the necessary information } \\
\text { from the Internet }\end{array}$ \\
\hline 3 & Possibility of using didactic materials & $\begin{array}{c}\text { Didactic materials like electronic textbooks, websites, } \\
\text { mobile games, presentations, etc. }\end{array}$ \\
\hline 4 & $\begin{array}{l}\text { Checking the knowledge on the subject with the } \\
\text { help of computer game }\end{array}$ & $\begin{array}{c}\text { Using multimedia technology helps in knowing the level of } \\
\text { knowledge gained on the subject. }\end{array}$ \\
\hline 5 & Formation of the level of knowledge and skills & $\begin{array}{l}\text { The formation of the level of knowledge and skills is a } \\
\text { process with practice. The teacher must have these levels. }\end{array}$ \\
\hline 6 & Depth of knowledge & $\begin{array}{l}\text { Internet browsing, video information, knowledge deepening } \\
\text { with the help of computers, smartphones }\end{array}$ \\
\hline 7 & Effective use of lesson time & $\begin{array}{l}\text { For effective use of time, much attention is paid to } \\
\text { multimedia technologies. Sometimes time is not enough, } \\
\text { teachers have to connect everything with time. }\end{array}$ \\
\hline 8 & $\begin{array}{l}\text { Children should work creatively so that they } \\
\text { develop according to their interests. }\end{array}$ & $\begin{array}{c}\text { Children must work creatively to develop their interests, be } \\
\text { able to use a variety of ready-made computer training } \\
\text { programs, websites, information technology. }\end{array}$ \\
\hline 9 & The acquisition of practical skills & $\begin{array}{c}\text { Practical skills master with computer game tasks, using a } \\
\text { variety of programs. }\end{array}$ \\
\hline
\end{tabular}

Methods of teaching the Kazakh language and literature are technologies related to the language used to establish and maintain relationships. The speaker uses interactive strategies to ensure interaction. For example, media (audio and video) are selected from specific methodological models and depending on the goals of language learning in accordance with the theory of linguistics and methodology. Library resources on the interactive whiteboard works contributes to the reproduction of the vocabulary of students when they work with a picture on it. The teacher and language learners control the material through a computer. For example, the pronunciation of a phonemic symbol of a certain word is checked, without translation it is possible to carry out work on enrichment of a lexical stock by means of drawing. Much attention is paid to the effective conduct of test works and much more. The advantages of using an interactive whiteboard in the lessons of the Kazakh language: saving time in the classroom, a closer presentation of the lesson material, access to a large number of sources of information in the shortest possible time [6]. Multimedia presentations are a very important direction in the methodology of teaching the Kazakh language. Multimedia consists of one of various information objects, such as text, graphics, video, animation, and sound. When preparing presentations in the Kazakh language, students acquire new knowledge and skills in the process of planning, designing. As a result of this work:

- exchange of experience;

- exchange of information;

- exchange of methods of solving problems;
- sharing the results of individual and joint projects and so on

In addition, it can be considered one of the new innovative technologies in communicating with students who could not attend classes for various reasons, through the Internet, the school website. Students and teachers can communicate by e-mail using various means of communication. On the website of the school the student is given the opportunity to give the passed topic through clusters.

Currently, for a user who simultaneously uses three fonts from the keyboard (Kazakh, Russian, Latin) is unacceptable. As the main driver of graphics computer records - Latin, the introduction of Latin script creates discounts to use the keyboard.

Switching to the Latin script requires a completely different approach to keyboard formatting. Since many letters of the Kazakh alphabet differ from Latin letters, that is, dots are added to the Latin letters (horizontal or vertical) or to the Latin letters. Thus, 24 characters of the Latin alphabet easily turn into 42 characters of the Kazakh alphabet.

On a computer, each uppercase letter, lowercase letter (characters) are distinguished by a code. The complexity of the programs on the computer, a large number of funds for their creation, the absence of the coding table of the original letters causes many difficulties. But one of the efficiency of the transition to Latin graphics-all letters facilitate the situation with the presence of major operating systems based on the alphabet. In this case, it will only be 
necessary to collect the original letters of the new Kazakh alphabet.

It is easy to create a printed interface on mobile devices. There can be 2-3 variants of different developers. Another problem is the language replacement registry on smartphones. If use 3 or 4 languages for recording on mobile phone, for example, changing the languages is very inconvenient for the iPhone, because user needs to enter the buttons on the print board to translate into other languages.

In the process of introducing a new Kazakh alphabet based on Latin graphics, there is a need to digitize all previously published works of textbooks, manuals and literature, as well as the number of scientific reports, technical regulations, archival documents. This contributes to the creation of an extensive digital database that stores all previously released information in the field of science, education, literature, history, medicine, etc.

Currently, many government agencies have information repositories. It is very important to legislate the storage of state information in state information repositories, and information of individuals, educational and scientific institutions in personal information repositories. As a result, it can be assumed that the cost of storing information in separate repositories will be cheaper, which reduces the cost of storing information in state information repositories. If the storage of personal information is built as a dedicated network, it increases the reliability and reduces the cost of storing information.

If the new Kazakh alphabet, based on Latin graphics, introduced any special graphic characters, for the full collection of all necessary information required national search engines. Such search engines could serve as a basis for the future development of a national search engine.

The appearance of digital versions of valuable collections in digital form will give impetus to the development of publishing in Kazakhstan. The change of printed sheets, leading to self-reformatting of books and publications, will be different, since the translation of the text from Cyrillic to Latin graphics requires the introduction of electronic design systems for electronic and paper publications. At the same time, the need for computer graphic design increases.

\section{RESEARCH RESULT}

Modern information and communication technologies are rapidly developing the Latin alphabet is the main and pragmatic tool, that promotes the establishment of relations that do not remove anyone from each other.

As a result of the research, the authors recommend several training tools. The first them, multimedia alphabet for the study of Latin graphics of school-age children (Fig.1). It helps preschool children to quickly learn the letters given by Latin graphics, and arouses interest in studying. All letters in the alphabet are represented by explanatory words and animated pictures. The multimedia alphabet, learning Latin graphics, allows to develop the language of preschool children, to expand the scope of application. In the alphabet, special attention is paid to the development of speech and thinking of children, expanding their horizons. During the event, the rich vocabulary of the native language, especially the use of words were considered.

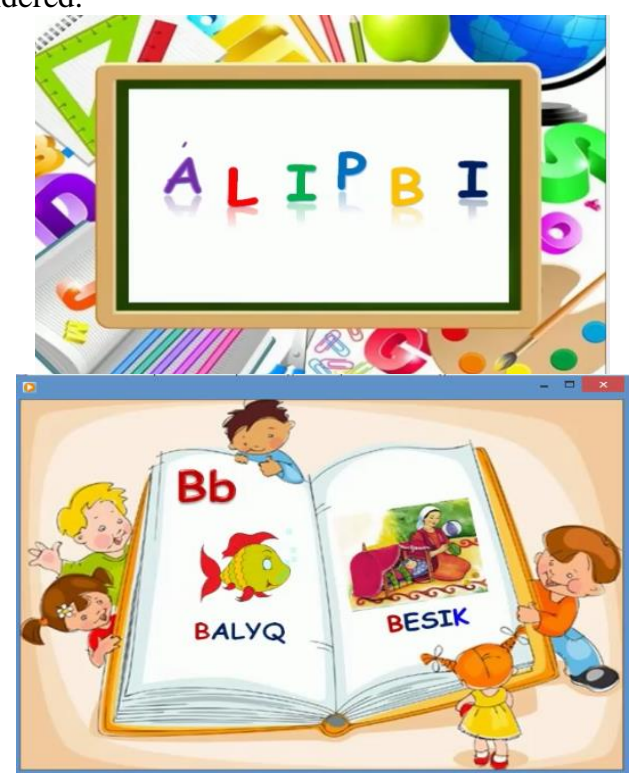

Figure 1 The multimedia alphabet for learning Latin alphabet

Secondly, for the development of this Latin graphics developed children's computer games and mobile applications. Developed mobile applications are widely used and are in great demand. This is one of the ways to optimize the process of adaptation of preschool children after learning the Latin alphabet using mobile applications. The first game is called «Find and write». In this game children will need to write the name of the found picture (Fig.4), after the simple drawings have been presented as a puzzle and properly placed.

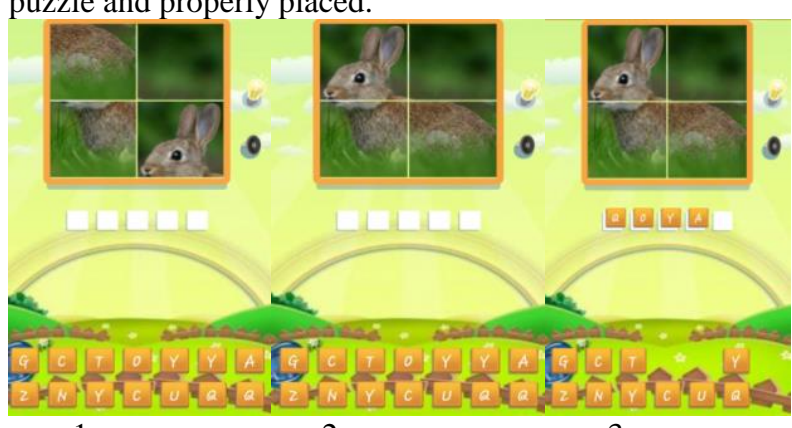
1- screen
2- screen
3- screen

Figure 2 Mobile game "Find and write" for learning the Latin alphabet

In computer games and mobile applications for children learning Latin, graphics are considered teaching the spelling rules and practical application of Latin graphics. In addition, the main result of this research is the preparation of digital electronic book accompanied by audio and video materials. 


\section{DISCUSSION}

The modern teacher is required not only to have a profound knowledge of his subject, but also historical cognition, teacher training-psychological, well-being, politicized economic knowledge and information literacy. He is proud of being a high educated and educated person only in the age-appropriate education, with a sense of genius, creativity, enthusiasm, and profound knowledge of the new technology of teaching. Therefore, today's requirement is the use of information and communication technologies, the development of knowledge.

The use of information and communication technologies in teachers' experience has allowed students to obtain the following benefits:

- comprehensively improves and develops knowledge through a variety of information, imagery, sound definitions;

- independently performs analytical tasks;

- attractiveness, continuous search and use of language disciplines;

- develops thinking, memory, discussion;

- performs various visual, pointing, instructive tasks;

- performs test tasks at various levels, tests their knowledge [7].

The main purpose of this research work is the study of the alphabet based on Latin graphics, the use of multimedia technologies. During the research analyzed educational game programs designed for computers and mobile phones. In 2017, the end point of this problem was set, a new alphabet was adopted and moving to the use of a focused, conscious national alphabet. Today, after the schedule was adopted, work is underway to train the younger generation. To educate the younger generation, it is necessary, first of all, to prepare teachers and lecturers [8].

The Philology and Computer Science specialists of the Kazakh National Women's Teacher Training University are working on the development of mobile applications for smartphones and textbooks, accompanied by multimedia technology for Latin alphabet teaching based on Latin graphics. The above mentioned mobile applications, tutorial programs have been tested for kindergarten teachers and elementary school teachers. Number of applicants, survey results.

Latin graphics is a symbolic basis of all modern languages, programs and all languages of ICT. Under the leadership of the National Commission for the Consciousness of the Public Consciousness, there is a detailed study of the program of transition to Latin graphics for 2018-2025. In the course of implementation of the same routes, the Kazakh National Women's Teacher Training University is working hard.

The research group conducted a review and analysis of the process of latinization in neighboring Turkic-speaking countries, the nature of the language policy of the country during this period. For instance, in Azerbaijan this step was taken immediately, in Uzbekistan this process lasted 20 years. After 25 years of independence, Kazakhstan began the transition to the Latin alphabet [9]. The great advantage of this solution is that it is combined with integration in the Latin-speaking space. Many Turkicspeaking countries switched to the Latin alphabet. It is much more efficient and convenient in matters of computerization. A conventional keyboard can be used without pads, which reduces the cost and reduces the operation time, such as typing [10]. While learning in Latin it will be easier to accept information. A large number of open resources in languages with Latin graphics will be achieved in the world educational space. Many universities make such resources for public use, and Latin writing is one way of conveying information. Analyzed the language situation before and after the transition to the Latin alphabet, carried out the definition of the main factors.

\section{CONCLUSION}

Summing up, it was determined the need to switch to the Latin alphabet when connecting the education system in Kazakhstan to the system of the world information space. First, to revise the composition of the sounds of the Kazakh alphabet and observe its natural laws. This can be achieved by switching to the Latin alphabet. It's a linguistic necessity.

Secondly, the lack of a variety of programming languages, database management system, text editors, coding tables nine Kazakh letters causes difficulties in working on the computer. This problem can be solved by switching to the Latin alphabet. This is a technical necessity.

After the adoption of Latin graphics, the research team of the project is working on the implementation of works aimed at the promotion and training of the Kazakh alphabet. When developing training programs and introducing them into testing, philologists take into account the linguistic nature of the Kazakh language, give scientific comments to the solution of problems arising in the designation of original signs, writing terms, marking introductory words, take into account the opinion of Turkic-speaking foreign and domestic philologists. The perception of graphics is carried out by solving problems related to spelling. At this stage, multimedia technologies, in particular, special training programs and mobile applications can become an auxiliary tool. In the future, as part of the implementation of the activities specified in the project schedule, work will continue to improve the experience of the research. We are confident that the main results of the research work will be valuable for the improvement, development and development of the Kazakh alphabet based on the Latin graphics. 


\section{ACKNOWLEDGMENT}

The article was written within the framework of the grant funding scientific project of the Ministry of education and science of the Republic of Kazakhstan on the topic "Linguistic foundations and multimedia technologies for the creation of interactive training programs associated with the transition to Latin graphics" (State registration number 0118 RK 00772, Program code AP05133194)

\section{REFERENCES}

[1] K. Zhubanov, Issledovaniya na kazahskom yazyke. Almaty: Nauka, $581 \mathrm{p}$.

[2] K. Kuderinova, Teoreticheskie osnovy pravopisaniya kazahskogo.-Almaty: «Centr razvitiya gosudarstvennogo yazyka», 2010, $380 \mathrm{p}$.

[3] Anar Fazylzhanova, Latyn alipbiine koshu Turkiya, Azirbaizhan, Ozbekstan elderinde kalai zhurgizildi? «Ana tili» gazeti, 24.01.2013

[4] Victoria Klement, «Alphabet Changes in Turkmenistan, 1904-2004» Everyday Life in Central Asia: Past and Present, 2007.

[5] Ahmet Alyaz, Latyn alipbiine kohudegi Turkiya tazhiribesi. «Akikat» gazeti, 27.06.2018

[6] R. Syzdykova, Abai shygarmalarynyn tili. Almaty: Gylym, 1968, 334 p.

[7] S.M. Kenesbayev, G.I. Salgarayeva, A.A. Makhmetova, S.N. Idrissov, B.Sabit, "Management of information software systems in the corrective work with children with disabilities", J. 1 Revista ESPACIOS, Venezuela (Scopus), 05/09/2017, Revista ESPACIOS. ISSN 07981015 vol. 38(46) (2017).

[8] S. Abdrahmanov, https://egemen.kz/.../158174uaqytpen-undesken-rukhani-ur.

[9] A.Zh. Dosanova, Latyn alipbii negizinde sauat ashu adistemesi, Pedagogika gylymdarynyn kandidaty gylymi darezhesin alu ushin dajyndagan dissertacijanyn avtoreferaty, Almaty, 2009, 30p.

[10] Learning with ICT: New perspectives on help seeking and information searching. dited by Minna Puustinen, Jean-François Rouet, vol. 53-4 (2009) 1011-1362. 